Eixo Roda, Belo Horizonte, v. 29, n. 1, p. 103-116, 2020

\title{
Major Cardoso e João Ternura: um encontro na alfaiataria
}

\section{Major Cardoso and Joũo Ternura: A Meeting at the Tailor's}

\author{
Marcos Vinícius Teixeira \\ Universidade Estadual de Mato Grosso do Sul (UEMS), Campo Grande, Mato Grosso \\ do Sul / Brasil \\ marcosteixeira@uems.br
}

https://orcid.org/0000-0001-7195-9655

Resumo: Apesar de se tratar de um texto não aproveitado na versão final do romance João Ternura, "O homem e seu capote", de Aníbal Machado, pode ser lido e estudado de forma independente como um conto. O episódio protagonizado por João Ternura se assemelha a determinadas cenas que o major Cardoso vive na novela coletiva $O$ capote do guarda, da qual participou o próprio Aníbal Machado no início dos anos 1920. No entanto, esta novela permaneceu inacessível aos leitores durante muito tempo, tendo sido reeditada somente nos anos de 2005 e 2006 . É possível supor que esta obra tenha sido uma fonte motivadora para a realização de "O homem e seu capote", o que ainda não foi investigado pela crítica literária. Nessa perspectiva, o objetivo deste artigo é estudar este conto em relação à referida novela, considerando-se o capote e as ocorrências ligadas a esse elemento nas duas narrativas. Espera-se contribuir para uma melhor compreensão do universo literário do escritor, especialmente em relação ao período que antecede a publicação de seu primeiro livro.

Palavras-chave: Modernismo brasileiro; Aníbal Machado; Major Cardoso; João Ternura.

Abstract: Despite being an unused text in the final version of the novel João Ternura, "O homem e seu capote", by Aníbal Machado, may be independently read and studied as a short story. The episode's protagonist is João Ternura and the text is similar to certain scenes in which Major Cardoso lives in the collective novella O capote do guarda, with which Aníbal Machado himself contributed in early 1920's. However, this novella remained inaccessible to readers for a long time, being reedited only in 2005 and in 2006. It is possible that this work was a source of motivation for writing "O homem e seu capote", which still was not investigated by the literary critique. In this perspective, this article aims to study this 
short story in its relation to the novella mentioned above, considering the Capote (or the Overcoat) and the instances related to this element in both narratives, addressing a better understanding the literary universe of this writer, particularly regarding the period before the publication of his first book.

Keywords: Brazilian modernism; Aníbal Machado; Major Cardoso; João Ternura.

Após quase 80 anos, o conto "O homem e seu capote", de Aníbal Machado, continua despertando o interesse da crítica e dos leitores. Considerado um episódio não aproveitado na constituição final do romance João Ternura, a editora José Olympio tomou o cuidado de reproduzi-lo como apêndice da obra, que foi publicada postumamente, reconhecendo o seu valor literário. $\mathrm{O}$ texto foi recomendado por Carlos Drummond de Andrade, que se encarregou da edição final do livro, e por M. Cavalcanti Proença. Este, em um texto de reconhecida importância, "Os balões cativos", comentou sobre o conto, afirmando que "O piano" seria uma "retomada do tema desenvolvido em 'O homem e seu capote"” (PROENÇA, 1997, p. xxiii).

Publicado em 1940 na Revista Acadêmica, o texto é bastante anterior ao romance que só seria publicado em 1965. Já o conto “O piano” apareceu em livro em 1944 e teve o texto revisto em 1959 quando foi publicado na obra Histórias reunidas. Além de Proença, vários estudiosos vêm dedicando atenção a "O homem e seu capote", dentre os quais estão os trabalhos de Yedda de Castro Brascher Goulart (1985), que estabelece uma relação com "O capote", de Nikolai Gógol; Adriana dos Santos Teixeira e Francis Paulina Lopes da Silva (2005), que estudam o conto em relação ao "O espelho", de Machado de Assis; e Luiza Vilma Pires Vale (2011) e Andréa Maria de Araújo Lacerda (2013), que comentam o texto, observando a relação indicada por Proença.

É possível assegurar que a afirmação de M. Cavalcanti Proença tem, acertadamente, norteado os estudos sobre o conto. Em seu texto, o crítico afirma ainda que "O piano" "documenta duas fases da evolução do escritor" (PROENÇA, 1997, p. xxiii). Sabemos pela editora José Olympio que "O homem e seu capote" foi publicado em 1940, conforme já pontuamos, mas é difícil mensurar a época em que foi escrito, pois Aníbal Machado já trabalhava em seu romance desde o início da década de 1920. Uma relação ainda não estabelecida, e que propomos aqui, ocorre entre "O homem e seu capote" e a novela coletiva $O$ capote do guarda da qual Aníbal Machado 
participou também no início da década de 1920. Talvez se possa pensar numa fonte para a gênese do conto, mais forte, em nosso entendimento, do que a relação já estudada, por exemplo, com o conto de Nikolai Gógol.

Entre "O piano" e "O homem e seu capote" ocorre um espelhamento, pois, apesar de se ter uma situação semelhante, que é a de livrar-se de um objeto, os dois protagonistas pertencem a universos completamente distintos e o tratamento dado à narrativa é também bastante diverso. Como veremos, a ideia de se livrar de um objeto, no caso, um capote, se liga a parte importante da novela $O$ capote do guarda. Diferentemente da ironia amarga, embora quixotesca, que encontramos em "O piano", em $O$ capote do guarda as situações se perfazem de um humor leve, chapliniano, tal como ocorre em "O homem e seu capote", o que relembraremos agora.

João Ternura é o protagonista do conto "O homem e seu capote" e o episódio se parece com as situações inesperadas que encontramos nos filmes de Charles Chaplin, como na cena da bandeira levantada por Carlitos em Tempos modernos, na qual o personagem se envolve de forma inesperada e tenta escapar ou fugir da situação. A dimensão social, inclusive, está no texto de Aníbal Machado. Como se percebe no romance João Ternura, há uma forte oposição entre o protagonista e seu primo rico Bernardo. Este é o primeiro dono do capote inglês. Utilizou-o na Europa e maneja bem os mecanismos do capitalismo. Enriquecido na então capital do Brasil, o Rio de Janeiro, o personagem rico se atormenta, no romance, com a proximidade eventual de seu primo pobre, que chegou à cidade portando cartas de recomendação e sem vontade de se integrar ao novo mundo que se descortina, que lhe vislumbra e oprime ao mesmo tempo. João Ternura não é engajado e contrário a esse sistema social. Tal qual o personagem de Chaplin, que ergue uma bandeira e se vê no meio de uma manifestação popular, Ternura é justamente contrário ao sistema por indiferença. Personagem das ruas, sua lógica é outra. Por isso o tratamento dado à narrativa é leve e o humor se faz presente. O leitor pode rir da situação do personagem ainda que se sensibilize com seu drama.

"O homem e seu capote" guarda relações com o romance, mas sobrevive separadamente como conto. Seu enredo é episódico: o tempo esfriou um pouco e Ternura resolveu vestir o capote que pertencera ao primo rico. Mas há o risco de o tempo mudar e a temperatura, como sói acontecer na cidade do Rio de Janeiro, aumentar. Podemos dividir o texto em duas partes. 
Na primeira, que vai do início até o meio do nono parágrafo, explica-se a origem do capote e delimita-se a temperatura de vinte e cinco graus como um limite para o uso da vestimenta. Até essa temperatura, o capote é uma máquina da felicidade, que o transforma, pela aparência, em rico temporário e lhe permite experimentar a cidade de forma diferente. Acima dos vinte e cinco graus, o capote pode lhe trazer aborrecimento e ser motivo de riso e de constrangimento. É o que passa a ocorrer no nono parágrafo: o capote lhe pesa, lhe faz suar e o expõe ao ridículo, pois a temperatura subiu e a cidade voltou ao seu normal. O que antes lhe envaidecia, agora o atormenta. É interessante observar como Aníbal Machado trabalha com a dimensão social, que, assim como aborda Antonio Candido em Literatura e sociedade, pertence à narrativa e integra a estrutura do conto. A indiferença está apenas em Ternura. A sociedade lhe observa de forma refratária: "Todos olhavam para Ternura com estranheza, como se o capote não lhe pertencesse, como se ele não tivesse direito a capote" (MACHADO, 1965, p. 227). Assim, o aumento da temperatura não só o constrange internamente, mas, ao evidenciá-lo pelo inusitado da situação, utilizar um capote em dia de sol, faz com que passe a ser visto como alguém fora das regras e, neste caso, a um passo da ideia de ilegalidade e de linchamento.

A narrativa, no entanto, se inclina para Ternura e atribui uma revelação da "alma verdadeira", do "espírito mau" do capote, que passa a lhe constranger. Para evitar ser notado como motivo de riso, o protagonista tenta se livrar do capote:

Capote mesquinho, coisa envenenada... - Toma ele para você, toma... - ofereceu-o a um motorneiro da Light. - Pois então não aceita? É ótimo, está quase novo.

O motorneiro respondeu malcriadamente, não queria saber de brincadeiras. - Toma então para você - disse a um pobre que não acreditou. Ofereceu-o também a um operário, que não o aceitou. Depois aos transeuntes em geral, como um maníaco. Ninguém queria saber do capote, e era incontestável que ainda estava bom. (MACHADO, 1965, p. 228).

É difícil se livrar do capote e as tentativas tornam engraçada a situação. Ao mesmo tempo, a dimensão social se mantém presente o tempo todo. O personagem pensa em largá-lo no asfalto e correr, mas não o faz por falta de coragem e porque "podia ser preso". Sabemos que o conto 
foi publicado em 1940, mas, como dissemos, é difícil presumir o período de sua escrita, que pode ser anterior. $\mathrm{O}$ sentimento de medo, no entanto, permite relacioná-lo com o conto "O piano" e, nesse sentido, com o período da Segunda Guerra. Ainda assim, Ternura procura por uma rua deserta e larga o capote após virar uma esquina. Livre do fardo, entra em um café onde se surpreende com moleques que vieram the trazer o traje perdido com a esperança de receberem uma gorjeta. Aníbal Machado consegue unir a situação inusitada de não conseguir se livrar da vestimenta à questão social. Se antes o capote poderia alçar o personagem à aparência de alguém importante, pertencente a uma classe rica, agora lhe atormenta justamente por isso, pois as crianças esperam uma boa gorjeta de quem talvez seja mais pobre do que elas próprias.

Ocorre, então, nova tentativa de se livrar do capote, que desta vez é abandonado "como a uma criança enjeitada" (MACHADO, 1965, p. 229) em um corredor escuro. Um menino se assusta e chora. Um guarda-civil aparece e o devolve a João Ternura, que agora terá que ir até o distrito dar explicações sobre a situação. Na manhã seguinte, é liberado e volta para sua morada vestindo o capote e novamente sendo vítima do riso alheio, pois fazia calor. Livre do traje, Ternura resolve sair "com vontade de correr, de voar" (MACHADO, 1965, p. 230). Rouba um bago de uva em uma casa de frutas, provoca a ira de um fruteiro que corre atrás dele. Juntam curiosos e alguém se lembra que ele usava um capote, que provavelmente teria furtado e grita "Pega o ladrão" (MACHADO, 1965, p. 230). A forma como Aníbal Machado finaliza o conto, com Ternura fugindo de uma multidão, é interessante. Por um lado, intensifica o roubo, provocando humor ao percebermos a movimentação de uma multidão por causa de um bago de uva. Por outro, intensifica o confronto em posições sociais, desnudando um preconceito existente na sociedade, que não conceberia a possibilidade de um vagabundo possuir um capote inglês. Neste caso, a característica é enfatizada fortemente, pois o protagonista está sem o capote e a lembrança é evocada. O capote se liga ao personagem mesmo pela ausência, o que revela, com humor, que ele não consegue se livrar da vestimenta nem mesmo quando não a usa.

Aníbal Machado participou da escrita de uma novela coletiva em que há situações em que um personagem também tenta se livrar de um capote. O capote do guarda é uma novela coletiva publicada na forma de folhetim 
no antigo jornal Estado de Minas, muito provavelmente em $1921 \mathrm{e} / \mathrm{ou}$ em $1922,{ }^{1}$ na cidade de Belo Horizonte, Minas Gerais. Hoje podemos ler a obra de forma incompleta, pois não se conservaram os cinco primeiros capítulos. Ainda assim, o texto resiste à leitura e desperta prazer e curiosidade, pois se trata de uma publicação relevante tanto para a história da capital mineira, que se constituía, quanto para a invenção de um Modernismo, que se iniciava. Foi Pedro Nava quem conseguiu cópia dos recortes do jornal e os preservou. Posteriormente devemos à Casa Rui Barbosa a preservação deste acervo e finalmente a Humberto Werneck, que os coletou e possibilitou a nova publicação. Hoje podemos ler a obra em quatro números da revista da Academia Mineira de Letras. Os dois autores também estudaram a novela e fornecem-nos informações relevantes tanto em Beira-mar (2003) quanto em $O$ desatino da rapaziada (2012).

Além de Aníbal Machado, participaram da novela coletiva os autores Carlos Góis, Ernesto Cerqueira, Laércio Prazeres, Berenice Martins Prates, João Lúcio e Milton Campos. Apesar de não termos hoje acesso aos cinco primeiros capítulos da novela, é possível compreender em boa medida o enredo. O início do capítulo VI, escrito por Carlos Góis, funciona como um início para a novela que nos chegou e à medida que vamos lendo a obra, vamos deduzindo questões das partes antecedentes. A história, no sexto capítulo, começa com D. Laura recebendo um convite para o marido, o major Cardoso, ir depor no inquérito instaurado para investigar a morte do tipógrafo Antônio Prestes. Há também uma carta misteriosa remetida por uma dona Maria, talvez a esposa do tipógrafo, mencionando um capote. Dois mistérios percorrem, assim, a narrativa: a morte de Antônio Prestes e o caso do desaparecimento de um capote.

No capítulo XII, escrito por Aníbal Machado, há um avanço temporal na narrativa, o que cria uma forte complicação no enredo. O escritor insere a gripe espanhola no enredo, atribuindo um aspecto mórbido para a cidade, que assiste ao desaparecimento de várias pessoas. Em determinado momento, o

\footnotetext{
${ }^{1}$ Ainda não é possível precisar com exatidão as datas de publicação dos capítulos da novela O capote do guarda. Lívia Guimarães Prazeres, que fornece informações a Pedro Nava, afirma que a obra pode ter sido publicada entre 1921 e 1924 (NAVA, 2003, p. 105). Joaquim Nabuco Linhares (1995, p. 192), no entanto, registra que o jornal no qual foi publicada deixou de existir em 12 de setembro de 1922. Nos exemplares preservados do jornal na Coleção Linhares não encontramos nenhum fragmento da novela.
} 
capote surge como assunto relacionado à gripe. Conhecemos então o antigo dono da vestimenta e somos informados do furto:

- Pois eu não tenho medo, disse o homem macilento, que se chamava Segismundo Temporão. E olhem, só uso roupa leve. Resfriado não me pega. Nunca usei capote.

Isto é, já usei quando pertenci à Guarda Civil, assim mesmo porque me deram de graça. Por sinal que mo roubaram; não sei se se lembram: foi em junho deste ano, por ocasião da morte meio misteriosa de um tipógrafo, um tal Antônio Prestes... Eu estava de plantão na Floresta; como havia muita briga e pancadaria na vizinhança, resolvi esconder-me num bar da rua Itajubá, para escorropichar uma sinhaninha e deixei o capote encostado na janelinha do tipógrafo; quando voltei, adeus capote! Sumiu. (REVISTA..., 2006b, p. 151).

No capítulo XIII, escrito por Carlos Góis, temos o depoimento do major Cardoso ao delegado dr. Breno. Talvez se trate de um dos melhores textos do livro, com uma narrativa envolvente e leve que nos lembra o gênero da crônica. Em tom de conversa amigável, o major Cardoso explica ao delegado que conhecia o tipógrafo desde o tempo da escola primária feita em Ouro Preto e que os dois saíam sempre para caçar, sendo ele um mau caçador e o falecido o contrário. Num dia de caçada, vem encontrar o amigo doente, que o desafia ironicamente a ir caçar sozinho e lhe trazer um simples jacu. O desafio é aceito, mas o major não consegue caçar nada. Resolve então furtar uma galinha d'angola do vizinho, mandar assá-la e entregá-la na casa do tipógrafo como se fosse um jacu. Para executar seu plano, o protagonista se lembra que o guarda-civil tinha o hábito de guardar seu capote escondido no seu jardim. Ele então veste o capote e segue para o galinheiro do vizinho. Lá, torce o pescoço de uma delas, a embrulha no capote e segue para o comércio Dia e Noite, onde combina o assado e a entrega do falso jacu na casa do tipógrafo. No outro dia depara-se com a notícia de que o amigo falecera com sintomas de envenenamento. Ao sair de casa, encontra galinhas mortas à espera da carroça de lixo e descobre assim que o vizinho jogara veneno para matar baratas, o que acabou comprometendo a própria criação de galinhas. Com o depoimento, o major é dispensado.

No capítulo seguinte, de Ernesto Cerqueira, o capote é novamente inserido na narrativa como algo que compromete o relato do major e que poderia revelar algo escandaloso que talvez envolvesse adultério e assassinato. 
- E o capote? Pensava.

Sim, porque o major não explicava por que cargas d'água o capote ficara em casa do tipógrafo...

D. Laura quis esclarecer-se e procurou a "carta fatal", que havia escondido na gaveta da cômoda. Achou-a. E tornou a ler o postscriptum: "Mandar-lhe-ei amanhã o capote."

(REVISTA..., 2006b, p. 156).

A partir deste momento, o capote passa a atormentar o major Cardoso, aparecendo-lhe de diversos modos e nas situações mais improváveis.

Na primeira cena, o major está acompanhado de Portilho, que estivera em sua casa antes de seguirem para o cinema. O amanuense Portilho está apaixonado por Laurinda, sobrinha do major, e espera obter, na aproximação com este, um auxílio para o futuro casamento, que também dependeria de uma promoção no trabalho. É a época do cinema mudo. Enquanto ocorre a projeção, a orquestra toca o Rigoletto e o major pensa em escrever um filme policial sob o título de $O$ Anarquista de Chapéu Coco, numa clara referência ao artista Charles Chaplin. Portilho pensa em escrever um soneto para a amada. Nesta ocasião, de forma completamente inesperada, surge um "indivíduo de luto fechado" (REVISTA..., 2006b, p. 163), que entrega um embrulho para o major afirmando que foi remetido por D. Maria, a viúva do tipógrafo.

O major, atormentado, decide sair do cinema. A narrativa que dá sequência, escrita por Milton Campos, apesar de anterior, permite lembrarmos do enredo de "O homem e seu capote":

E saíram os três: o Major, o Portilho e o embrulho.

Tinha chegado o trem. Grupos, à porta do Giácomo, esperavam os jornais. Cardoso entrou, afobado, e pediu: Chácaras e Quintais.

Curvou-se sobre o balcão e, enquanto corria um olho distraído pelos galináceos e arbustos, foi, com o cotovelo, empurrando o embrulho fatídico para um cantinho discreto da prateleira.

Aí, o Major sorriu, aliviado. Desfizera-se da enrascada. [...]

$\mathrm{E}$, dissertando com calor sobre a galinha indígena, foi saindo, devagarinho. Mas o prestimoso Portilho, sempre pronto a agradar o chefe e futuro tio, lembrou:

- Ó major! O embrulho ia ficando.

Cardoso quase teve uma síncope de ódio. (REVISTA..., 2006c, p. 103). 
Em seguida, major Cardoso, alegando que precisa se encontrar com alguém importante, pede que Portilho leve consigo o embrulho e o guarde em sua casa. Este pega então um bonde, que ao passar pela avenida Cristóvão Colombo perde os freios. $\mathrm{O}$ amanuense cai do bonde, rola na poeira e resolve ir caminhando para casa. No caminho, sujo e segurando o embrulho, é interrogado por um policial, que pede para que o embrulho seja aberto, revelando um capote de guarda-civil. Portilho é encaminhado para a delegacia para prestar esclarecimentos. Lá vive a angústia da dúvida machadiana, à maneira de Porfilho de "O alienista": se disser que é amanuense e for fichado, poderá comprometer o seu casamento. Se disser que o capote pertence ao major e envolvê-lo no registro policial, poderá perder o seu apoio. Se não falar nada, poderia ser preso. Decide então dar um nome falso, o que é pior, pois o nome inventado coincide com o nome de um criminoso procurado pela polícia. É preso e só será liberado quando aparece o dr. Breno, que o reconhece e ri da situação na qual o amigo se envolveu. O nome do major Cardoso, no entanto, acabou sendo revelado: “O dr. Breno retirou-se, tendo antes recomendado que levassem o embrulho no outro dia cedo à casa do Major Cardoso" (REVISTA..., 2006c, p. 108). Em seguida o narrador dá voz ao major, que, monologando, pensa em dar sumiço ao capote no dia seguinte.

No penúltimo capítulo, de autoria de Aníbal Machado, narra-se uma surpreendente festa à noite na casa do major. No auge da festa, surge um guarda-civil e entrega um embrulho para o anfitrião:

Numa roda de maliciosos:

-O homem hoje está divertido...

-É, mas o caso do capote mesmo ele não explica...

- Que capote?!...

Cardoso olhou para o retrato de D. Emerenciana como quem pedia licença, virou-se para a sala e exclamou intimamente:

- Eta vida! Libertas quae sera tamen...

Nesse momento, surgiu na porta da sala um guarda-civil com um embrulho nos braços, dirigiu-se para o major, fixou-o, e segurando-o, falou em voz enérgica e firme:

- Seu major Cardoso! Repetiu - Major Cardoso!

E por fim:- Cardoso!

O major ficou estarrecido. Arregalou o olho esquerdo, que era o que melhor funcionava, e parou no meio da sala, hirto, frio, incomunicável.

D. Laura teve chilique. [...]

(REVISTA..., 2006c, p. 110-111). 
No último capítulo, escrito por Carlos Góis, somos informados de que o embrulho recebido pelo major no meio da festa continha livros e papéis relacionados à eleição que ocorreria no dia seguinte de um deputado "já previamente indicado e previamente eleito" (REVISTA..., 2006c, p. 112). Com isso, causa estranhamento a informação anterior de que o delegado teria mandado entregar o capote na casa do major, sendo um capote de um guarda-civil. No último capítulo é feito um reparo, digamos, sobre isso. Explica-se que o capote ficara no comércio Dia e Noite, que foi confiado ao gerente para que este mandasse remeter o capote para a casa do próprio major e que por engano foi parar na casa do tipógrafo. Relembra-se rapidamente a "dolorosa via crucis" pela qual passou Portilho para reparar, alterar ou dar nova interpretação à fala do delegado, que já reproduzimos aqui, acerca do destino final do capote:

De posse do capote, o delegado verificou pelo número da chapa a sua procedência - coincidia o número com o do guarda Nestório Rimes, de ronda na Serra e imediações. Mandou-o vir à sua presença e ordenoulhe explicasse o descaminho daquele "complemento do uniforme" (não houvesse ele vendido ou empenhado aquele acessório de sua representação em público?).

À vista do capote, o pobre guarda respirou desopresso. E explicou-se:

Deixara-o, como era velho hábito, guardado no jardim da casa do major Cardoso. Ao recolher da ronda procurou-o e deu-lhe por falta. Quis indagar do major, mas este se achava acomodado. Entrou logo de supor que algum "punguista", valendo-se do portão não ter chave nem tranca, o "suspendera", e estava em diligência por encontrá-lo.

$\mathrm{O}$ dr. Breno deu-se por satisfeito com a explicação, mas não deixou de advertir que, para o futuro, zelasse com mais cuidado as "vestes do cargo".

(REVISTA..., 2006c, p. 112).

Diferentemente do que se poderia supor sobre a fala do delegado presente no capítulo XVII, é preciso supor a existência de dois embrulhos para que a coerência seja mantida. Outro estranhamento que o último capítulo produz está no nome do guarda, que aqui se chama Nestório Rimes, diferentemente do anunciado por Aníbal Machado no capítulo XII: Segismundo Temporão. Em todo caso, é possível que a diferença dos nomes 
passe desapercebida não só por Carlos Góis como por muitos leitores pelos quais a obra tenha passado ou passará, posto que ainda é pouco conhecida ou difundida e seu acesso, apesar da edição existente, ainda é bastante restrito. Trata-se de característica recorrente no romance folhetinesco, que aqui pode ter sido fortalecida pela dimensão de coletividade: a ideia de a ação ter maior importância e cuidado do que a constituição do personagem, que tende a apresentar pouco aprofundamento e complexidade. De modo semelhante, referindo-se apenas ao romance de folhetim, Antonio Candido afirma:

Como sabemos, em muitos romancistas de alto nível o personagem se revela em parte através do acontecimento, que surge a modo de suporte da sua verdade humana e ocasião para podermos apreendê-la. Qualquer leitor de Stendhal sabe disso, e se deleita, na Chartreuse de Parme, com as intrigas da corte ducal, as fugas, prisões, manobras, lutas. O autor vai comentando, apontando o significado humano da situação, desvendando a propósito o personagem, mostrando o seu amadurecimento ou simplesmente o seu imprevisto. Não se trata disso, porém, na esfera folhetinesca, onde, por uma inversão de perspectiva, o personagem é que serve ao acontecimento. Este adquire consistência própria, impõe-se em bloco, incorpora o personagem e apela para o que há de mais elementar no leitor, confundido nesta hora à criança, ao homem rústico, ao primitivo, na fascinação pela magia gratuita da fábula. (CANDIDO, 2000b, p. 113).

É interessante pensar que, conforme afirmou Antonio Candido, a esfera do acontecimento ganha relevância no romance folhetinesco. $\mathrm{O}$ crítico estuda na ocasião o romance $O$ filho do pescador, de Teixeira e Sousa, mas sua afirmação pode ser relacionada, de fato, para outras obras do próprio Romantismo, como, por exemplo, O guarani, de José de Alencar. Curiosamente, explica o defeito de uma obra coletiva como Brandão entre o mar e o amor (1942) e o mérito de outra, também coletiva, $O$ mistério dos MMM (1962). É interessante notar, nesse sentido, como o universo do romance policial se adequa bem ao folhetinesco. Em O capote do guarda, é justamente a história de uma morte e a do furto de um capote de um guarda que torna o enredo instigante. As outras questões, que não abordamos neste texto, são de ordem complementar neste caso.

Em $O$ capote do guarda, como vimos, depois que a história da morte do tipógrafo ganha boa elaboração no capítulo XIII, de Carlos Góis, o interesse maior recai sobre a história do capote e o seu percurso 
ao longo da novela. Parece causar azar a quem o possui, despertando uma mística de objeto maldito, como se pode observar no episódio de Portilho, que não só se acidenta no bonde como acaba preso e pode ser vítima de constrangimento no trabalho, se os colegas souberem do episódio. Sempre esquecido ou abandonado pelo major Cardoso, parece insistir em voltar-lhe como o capote de João Ternura em "O homem e seu capote". É possível que a ideia de um capote alheio que nunca abandona o seu novo dono tenha sido aproveitada por Aníbal Machado em seu conto. Diferentemente de $O$ capote do guarda, João Ternura é apontado como possível ladrão de algo que lhe pertence. Como vimos, a dimensão social presente na narrativa como matéria constitutiva da trama é essencial para a acusação que lhe é feita.

Em $O$ capote do guarda, a situação social do major Cardoso é completamente outra. Ainda que sua titulação verdadeira, na novela, seja de capitão, Cardoso pertence a uma classe abastada nos primórdios da capital mineira. A narrativa, ao final, ao revelar que o embrulho entregue ao major durante a festa possui justamente o mecanismo para uma eleição forjada, sintetiza e denuncia o período da Primeira República. Assim, as relações sociais vão se dando por um jogo de influências e compadrios, que nos faz pensar que a proximidade de Portilho ao major lhe fará obter resultados não só no amor como no trabalho, em que o primeiro pode, inclusive, complementar o segundo. Afinal, seu casamento depende de uma promoção e um maior ganho financeiro. A família do major, e, neste caso, d. Laura, possui um papel muito importante. Apresenta-se como a tradicional família mineira, tão comentada por Pedro Nava em suas memórias. Cria-se um jogo de aparências, em que o protagonista precisa cuidar da honra da família frente à opinião pública. A acusação de furto ou de apropriação de um capote da Guarda Civil é diminuída quando o contexto histórico é evocado e o papel do major é pontuado nesta sociedade. Passa de crime a pequena infração. Ao final, apenas o guarda é retaliado verbalmente e aconselhado a tomar mais cuidado.

João Ternura é justamente o que está abaixo em qualquer gradação social. Espécie reflexiva de vagabundo, transita pelas ruas indiferente aos mecanismos da grande cidade e do capitalismo. A ele, o capote do primo rico inicialmente representa uma espécie de passaporte temporário ao mundo dos abastados ou de alguém como o major Cardoso. No entanto, é traído pela temperatura, que sobe. $\mathrm{O}$ capote, antes favorável, passa a constrangê- 
lo e expô-lo nas ruas do Rio de Janeiro não como alguém ligado à elite, mas como possível usurpador do bem alheio. A sociedade que lhe rodeia o denuncia pelo que tem, mas acredita que não deveria ter. Já major Cardoso poderá ver a questão do capote cair no esquecimento, ainda que, para um homem de seu grupo social, muito envergonharia o roubo de uma vestimenta e de uma galinha. Para ele, o crime é reduzido ao irrisório e esquecido ou perdoado. Embora se trate de texto de autoria coletiva, mas com participação de Aníbal Machado, o reaparecimento da novela $O$ capote do guarda pode agora participar como um primeiro patamar dos apontamentos que a crítica vem fazendo entre os contos "O homem e seu capote" e "O piano".

\section{Referências}

AMADO, Jorge et al. Brandão entre o mar e o amor. São Paulo: Livraria Martins, 1942.

CANDIDO, Antonio. Formação da literatura brasileira. 6. ed. Belo Horizonte: Itatiaia, 2000b.

CANDIDO, Antonio. Literatura e sociedade. 8. ed. São Paulo: Publifolha, 2000a.

CORREAA, Viriato et al. O mistério de MMM. Rio de Janeiro: Edições de Ouro, c1962.

GOULART, Yedda de Castro Brascher Goulart. O piano: de Aníbal Machado - gênese do conto e variações. 205f. 1985. Dissertação (Mestrado em Letras

- Literatura Brasileira) - Departamento de Língua e Literatura Vernácula, Universidade Federal de Santa Catarina, Florianópolis, 1985.

LACERDA, Andréa Maria de Araújo. O espaço ficcional em contos de Aníbal Machado. 198 f. 2013. Tese (Doutorado em Literatura e Cultura) Universidade Federal da Paraíba, João Pessoa, 2013.

LINHARES, Joaquim Nabuco. Itinerário da imprensa de Belo Horizonte 1895-1954. Belo Horizonte: Fundação João Pinheiro; UFMG, 1995. 587p.

MACHADO, Aníbal. Histórias reunidas. Rio de Janeiro: José Olympio, 1959.

MACHADO, Aníbal. João Ternura. Rio de Janeiro: José Olympio, 1965.

NAVA, Pedro. Beira-mar. 5. ed. São Paulo: Ateliê Editorial, 2003. 
PROENÇA, M. Cavalcanti. Os balões cativos. In: MACHADO, Aníbal. A morte da porta-estandarte, Tati, a garota e outras histórias. 15. ed. Rio de Janeiro: José Olympio, 1997. p. xiii-xxxiii.

REVISTADAACADEMIA MINEIRA DE LETRAS. AML, Belo Horizonte, a. 83, v. 38, out./dez. 2005. (Publicação parcial de O capote do guarda contendo textos de Carlos Góis, Ernesto Cerqueira e Laércio Prazeres).

REVISTA DAACADEMIA MINEIRA DE LETRAS. AML, Belo Horizonte, a. 84, v. 39, jan./mar. 2006a. (Publicação parcial de O capote do guarda contendo textos de Berenice Martins Prates e João Lúcio).

REVISTA DAACADEMIA MINEIRA DE LETRAS. AML, Belo Horizonte, a. 84, v. 40, abr./jun. 2006b. (Publicação parcial de O capote do guarda contendo textos de Aníbal Machado, Carlos Góis, Ernesto Cerqueira e Laércio Prazeres).

REVISTA DAACADEMIA MINEIRA DE LETRAS. AML, Belo Horizonte, a. 84, v. 41, jul./set. 2006c. (Publicação parcial de O capote do guarda contendo textos de Milton Campos, João Lúcio, Aníbal Machado e Carlos Góis).

TEIXEIRA, Adriana dos Santos; SILVA, Francis Paulina Lopes da. Jacobina e João Ternura: da vaidade à metamorfose. Revista Gláuks, v. 5, n. 2. p. 203212, 2005.

VALE, Luiza Vilma Pires. Concepções estéticas de Aníbal Machado: a originalidade criadora em seus contos. 246f. 2011. Tese (Doutorado em Letras) - Instituto de Letras, Universidade Federal do Rio Grande do Sul, Porto Alegre, 2011.

WERNECK, Humberto. O desatino da rapaziada: jornalistas e escritores em Minas Gerais (1920-1970). 2. ed. São Paulo: Companhia das Letras, 2012.

Recebido em: 25 de junho de 2019. Aprovado em: 28 de agosto de 2019. 